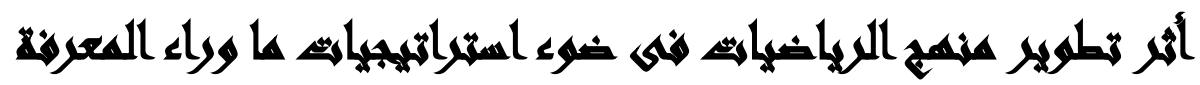

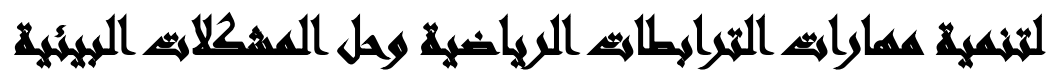

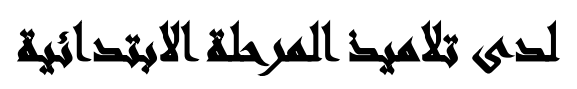

[10]

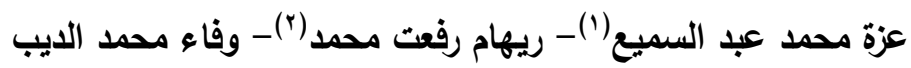

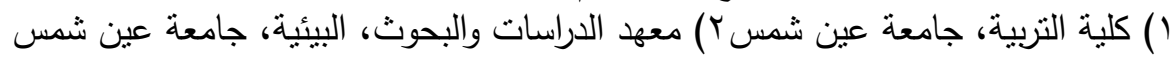

\section{المستصنص}

يهدف هذ البحث إلى قياس أثز تطوير منهج الرياضيات فى ضوء استراتيجيات ما وراء

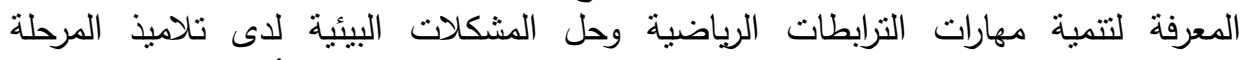

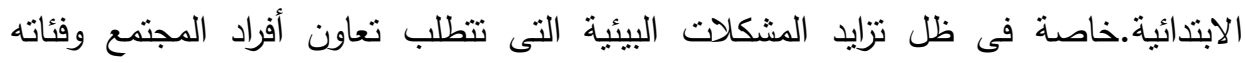

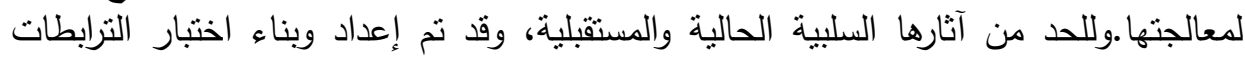

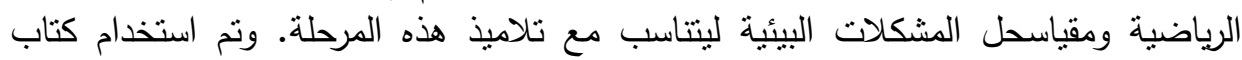

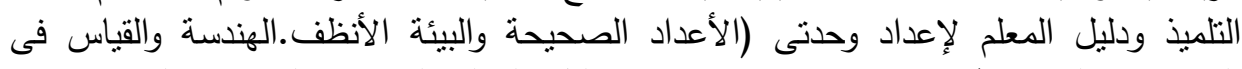

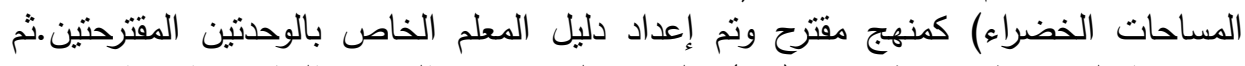

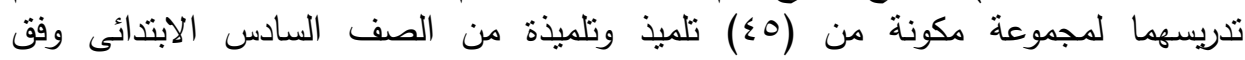

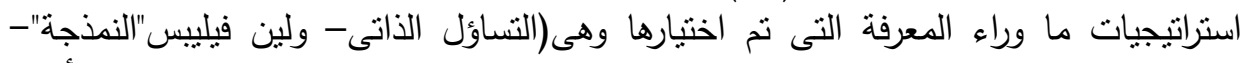

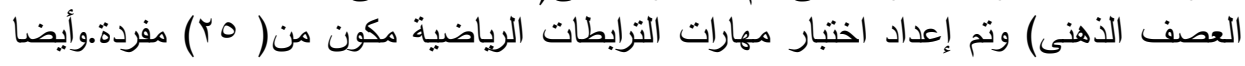

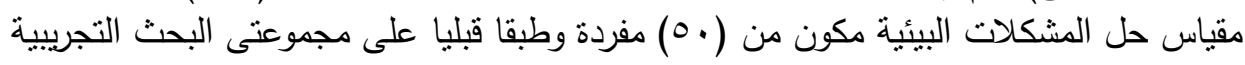

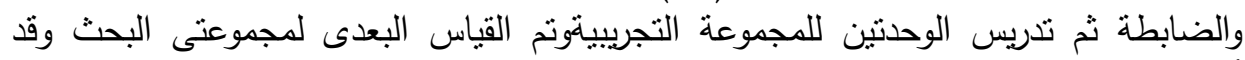

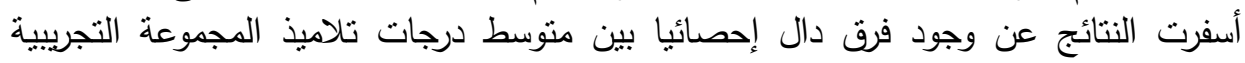

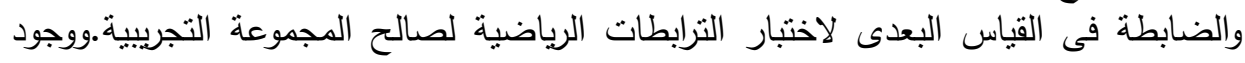

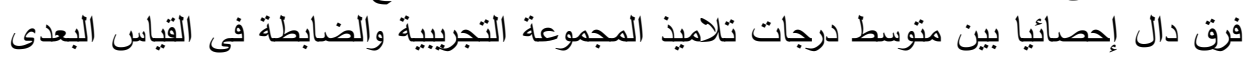

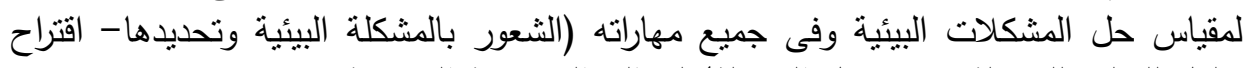

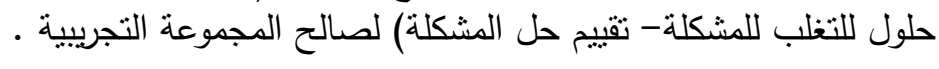




\section{Iatid}

تعد عملية تطوير المناهج التعليمية فى ضوء المتغيرات الحديثة ضرورة ملحة تهدف إلى متابعة النطورات المعرفية فى كل صنوف المعرفة العلمية خاصة فيما يتعلق بطرائق التدريس وأساليبها المتتوعة التى تركز على أساس تتمية مهارات التفكير الرياضى وحل المشكلات ومن بينها المشكلات البيئية وهذا بدوره يفرض تحديات تتطلب البدء باتخاذ خطوات سريعة من أجل

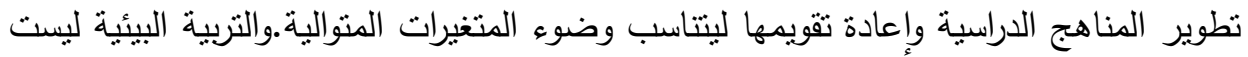
مسئولية مادة دراسية أو أخري ولكنها مسئولية جميع المواد بالقدر الذي يناسب طبيعة كل مادة وحدودها ودرجة اتصالها بقضايا ومشكلات البيئة .

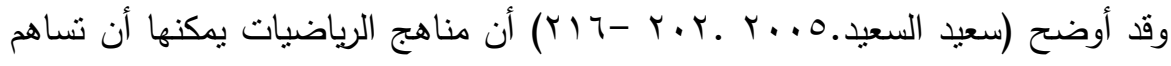
في تحقيق أهداف التربية البيئية بمرحلة التعليم الأساسي وذلك بتتاولها للقضايا والمشكلات البيئية الرئيسية في مصر من خلال تدريس بعض الموضوعات الرياضية كالإحصاء والنسبة والمساحة والمحيط وحساب المكسب والخسارة والموازين والمقاييس بولكي تتجح مناهج الرياضيات في تحقيق أهداف التربية البيئية ينبغي تعاون معدو ومطورو مناهج الرياضيات مع المختصين بإعداد وتطوير المناهج الدراسية الأخري.

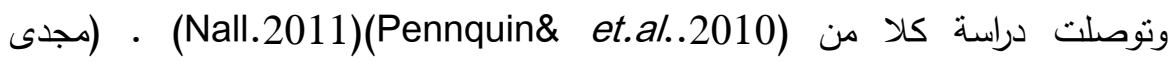

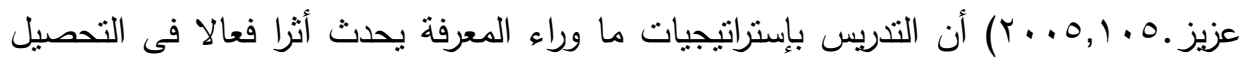

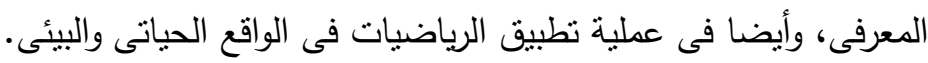

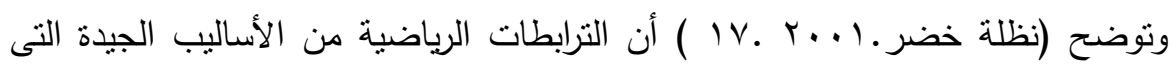
تعمل على تتمية قدرة التلميذ على التفكير وحل المشكلات وتساعدهم على تعلم ذى معنى للرياضيات وذلك من خلال توظيفهم للمفاهيم والتعميمات والمهارات الرياضية السابقة وربطها بالتثنيلات لتكوين المعرفة الجديدة .وبهذه الطريقة يسنطيع التلميذ روية الرياضيات كبناء معرفي منرابط. 
وتتضح العلاقة بين الترابطات الرياضية وحل المشكلات البيئية من خلال تحليل الخطوات التى يقوم بها التلميذ أثناء حل المشكلة حيث يبدأ التلميذ فى محاولة حل المشكلة التى نواجهه •وذلك بإستخدام مجموعة من المعلومات والخبرات السابقة لديه ويبدأ فى تكوين القواعد أو لون. المبادئ العامة لحل المشكلة، وهنا يظهر دور الترابطات المعرفية فى تتظيم وتكوين القواعد

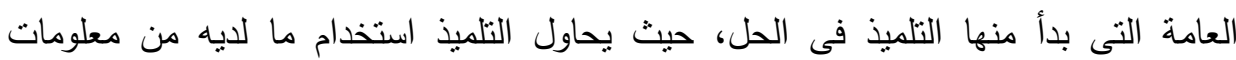

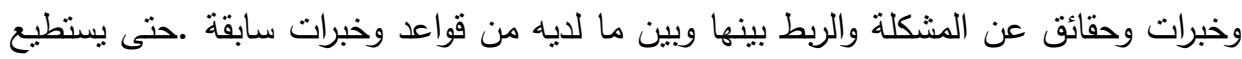

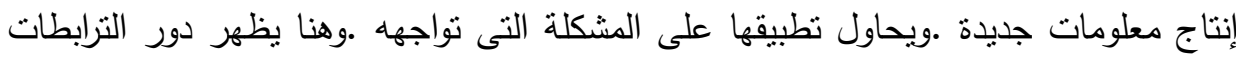
البينية فى محاولة تطبيق القواعد العامة على المشكلة التى أمامه.

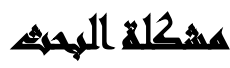

شعر الباحثون بمشكلة البحث وللتأكد من وجود المشكلة تمما يلى:

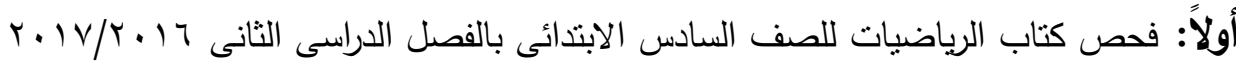
والذى يتكون من عدد ؛ وحدات بإجمالى VI درسا وقد تنين:

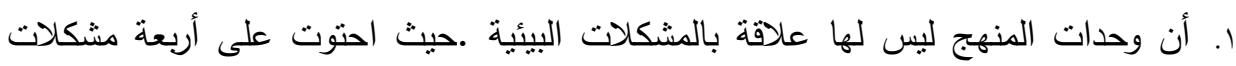
بيئية تم تتاولها كمثال أو مسألة خلال الدروس. r. أنه لايوجد ارتباط بين الرياضيات والمواد الأخرى سوى مثال واحد لمادة العلوم وأخر للمادة التربية الرياضية. ثانياً: مقابلة عدد (•0) معلم من معلمى الرياضيات بإدارة بنها التعليمية والقائمين على تدريس الصف السادس الابتدائى وسؤالهم عن استخدامهم لاستراتيجيات ما وراء المعرفة أثناء التدريس وعن مدى ما يتضمنه المنهج من مشكلات بيئية وترابطات رياضية وخاصة مع المواد الدراسية

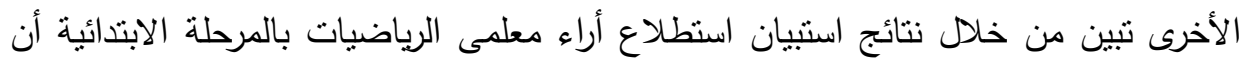

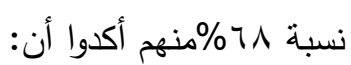
• التدريس قاصر على الإجراءات التقليدية وأن المعلمين يهتمون بالنتائج دون النظر إلى الى الكيفية التى جعلت هذا الناتج صحيح.

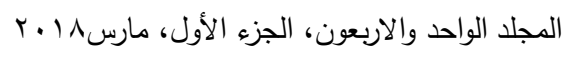


• المنهج لا يتضمن مشكلات بيئية واضحة ولا يوجد ترابطات رياضية مع المواد الدراسية الأخرى.

للالك يحاول البحث الحالى الجمع بين ما توصلت إليه نتائج الدراسات السابقة وما أكدت

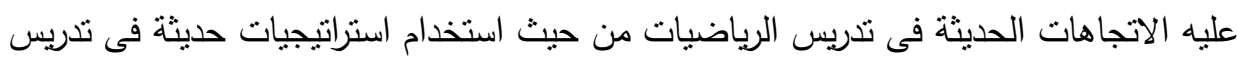

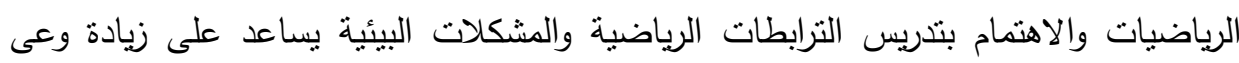

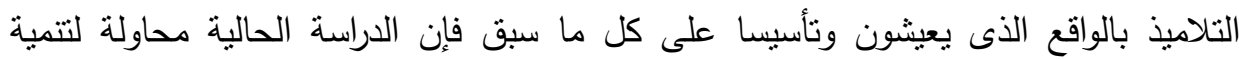

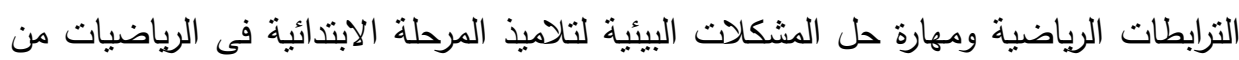
خلال التدريس باستراتيجيات ما وراء المعرفة.

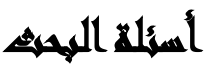

1- ما الأسس التى يمكن فى ضوئها تطوير منهج الرياضيات للصف السادس فى المرحلة الابتدائية؟

r- ما التصور المقترح لهنهج الرياضيات لتلاميذ الصف السادس بالمرحلة الابتدائية فى ضوء استراتيجيات ماوراء المعرفة؟ ماتهون r- ما صورة وحدتين من التصور المقترح لمنهج الرياضيات لتلاميذ للصف السادس بالمرحلة الابتدائية فى ضوء استراتيجيات ماوراء المعرفة؟ وحنج ع - ما فاعلية التصورالمقترح لمنهج الرياضيات فى تتمية مهارات الترابطات الرياضية لتلاميذ الصف السادس بالمرحلة الابتدائية؟ 0ـ ما فاعلية التصورالمقترح لمنهج الرياضيات فى تنمية مهارات حل المشكلات البيئية لتلاميذ الصف السادس بالمرحلة الابتدائية؟

\section{هروض المهيه}

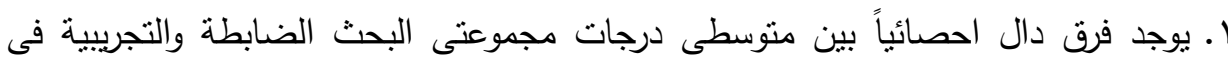
التطبيق البعدى في اختبار الترابطات الرياضية لصالح المجموعة التجريبية.

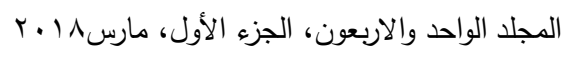


r. يوجد فرق دال احصائياً بين منوسطى درجات مجموعتى البحث الضابطة والتجريبية فى التطبيق البعدى لمقياس مهارات حل المشكلات البيئية لصالح المجموعة التجريبية.

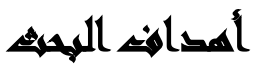

تتمية مهارات الترابطات الرياضية وحل المشكلات البيئية لدى تلاميذ المرحلة الابندائية

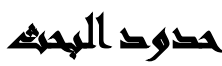

1-مجموعة من تلاميذ الصف السادس الابتدائى بمدرسة ابن خلدون الابتدائية التابعة لإدارة بنها التعليمية بمحافظة القليوبية. Y-وحدتى " الأعداد الصحيحة "."الهندسة والقياس " من محتوى كتاب الرياضيات للفصل

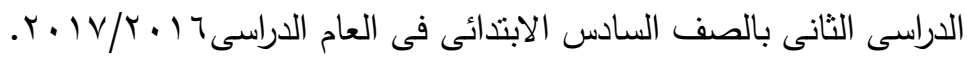

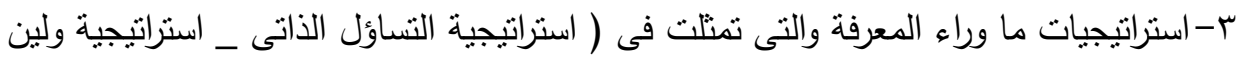

$$
\text { فيليبس (النمذجة)- استراتيجية العصف الذهنى ). }
$$

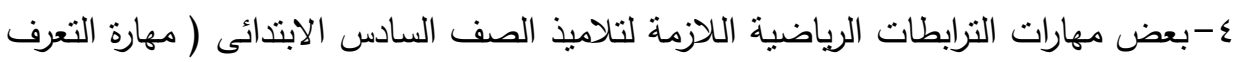

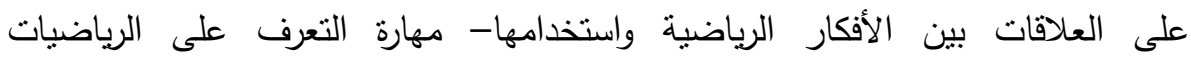

$$
\text { واستخدامها فى البيئة - مهارة التعرف على الرياضيات واستخدامها فى العلوم الاخرى ). }
$$

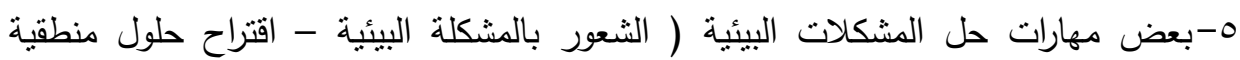
للمشكلة - تقيييم حل المشكلة).

\section{أهمية المهمث}

أولا: التلاميذ وذلك من خلال: 1. تحسين مستوى مهارات الترابطات الرياضية لاى تلاميذ الصف السادس الابتدائى. r. تحسين مستوى مهارات حل المشكلات البيئية لدى تلاميذ الصف السادس الابتدائى. 
ثانياً: معلمى الرياضيات وذلك من خلال: 1. الاستفادة من الوحتثينما بشملا من أهداف ومحتوى ووسائل وأنشطة تعليمية وأساليب النقويم في تدريس الرياضيات. r. الإنتفادة من اختبار الترابطات الرياضية ومقياس مهارات حل المشكلات فى نقويم تعليم تلاميذ المرحلة الابتدائية. ثالثاً: مخططى المناهج وذلك من خلال:

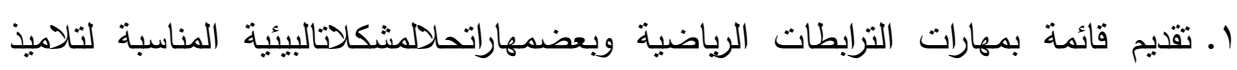
المرحلة الابتدائية والتى يمكن تتميتها من خلال منهج الرياضيات.

\section{همطللحاهي المهنه}

استراتيجيات ما وراء المعرفة "Metacongnitive Strategies": وتعرف إجرائيا فى هذا البحث على أنها "التفكير في كيفية معالجة المشكلات الواقعية البيئية باستخدام الرياضيات. والوعي بالاستراتيجية التي نختارها ونستخدمها للوصول إلي الحل. والأسئلة التي نسألها لأنفسنا عن المشكلة، وهي تتضمن المعرفة حول المعرفة (المعرفة التصريحية. المعرفة الإجرائية.

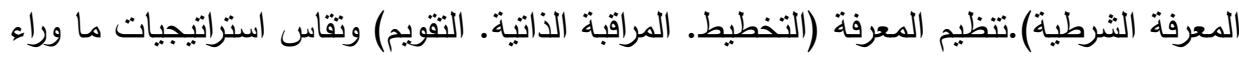

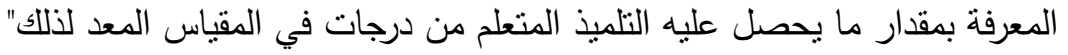

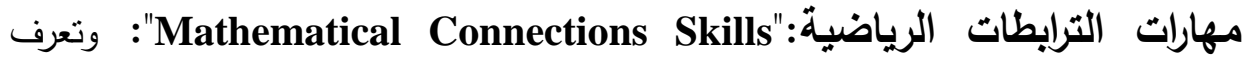

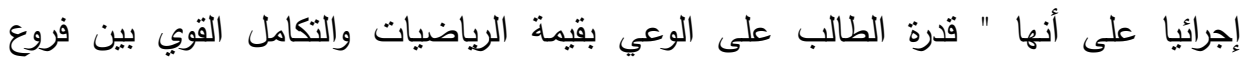
الرياضيات والمواد الدراسية الأخرى بجميع أنواعها والبيئة المحيطة بها لإنها ".

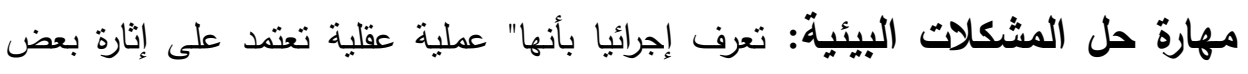

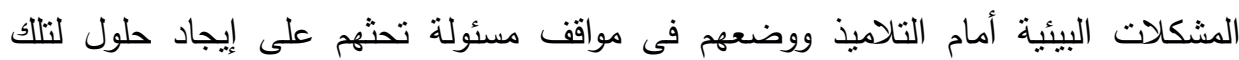
الشككلات وفق سلسلة من الخطوات والإجراءات حتى يتمكنوا فى النهاية من تقديم حلول إيجابية

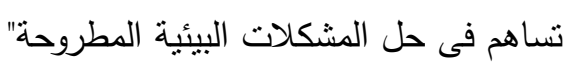




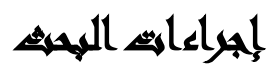

للإجابة عن الأسئلة والتحقق من صحة فروضه سار البحث وفق الخطوات التالية: أولاً: تحديد الأسس التى يمكن فى ضوئها تطوير منهج الرياضيات فى المرحلة الابتدائية: وتم الإجابة عن هذا التساؤلمن خلال: ا. دراسة نظرية لاستراتيجيات ماوراء المعرفة ومهارات الترابطات الرياضية ومهارات حل هل الإبه

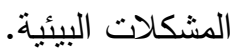

r. مراجعة الدراسات والبحوث السابقة المرتبطة بموضوع البحث. r. دراسة طبيعة الرياضيات وأهداف تدريسها بالمرحلة الابتدائية. ع. دراسة خصائص تلامبذ المرحلة الابتدائية.

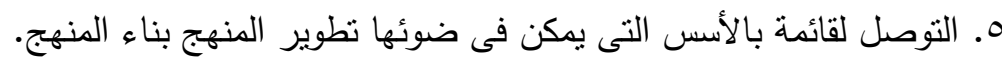
ومن خلال المصادر السابقة نم استخلاص الأسس والتى يمكن فى ضونى فئها نطوير منهج الرياضيات وبذلك يكون قد نم الإجابة على السؤال الأول للبحث. ثانياً: إعداد التصور المقترح لمنهج الرياضيات فى ضوء الأسس السابقة لتنمية مهارات الترابطات الرياضية وحل المشكلات البيئية لاى تلاميذ المرحلة الابتدائية: ونم الإجابة عن هذا النساؤل من خلال: ا ـ تحليل محتوى منهج الرياضيات لتحديد جوانب التعلم المتضمنة به: تم تحليل محتوى كتاب الرياضيات المقرر على تلاميذ الصف الساد الابتدائى الفصل الدراسى الثانى طبعة

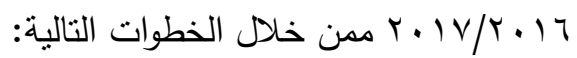

أ. تحديد هدف التحليل: هدف تحليل المحتوي إلى تعرف مدي توافر مهارات الترابطات الرياضية والمشكلات البيئية فى منهج الرياضيات بالصف السادس الابتدائى.

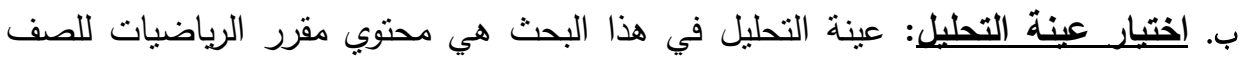

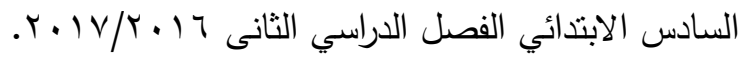


ج. تحديد وحدة التحليل: تمثلت وحدة التحليل في هذا البحث فى تحديد المسألة التي تكثف عن: • مهارات الترابطات الرياضية اللازمة لتلاميذ الصف السادس الابتدائى. • مهارات حل المشكلات البيئية.

د. صدق استمارة التحليل: للتأكد من نتائج التحليل.تم الاعتماد على إجراءات الصدق التنازمي حيث قامت الباحثة بعملية التحليل ثم استعانت بأحد المتخصصينفى مجال الرياضيات للقيات التيام بنفس عملية التحليل. وبعد الانتهاء من التحليل نم استخدام معادلة هولستى لحساب الصدق( رشدى طعيمه،

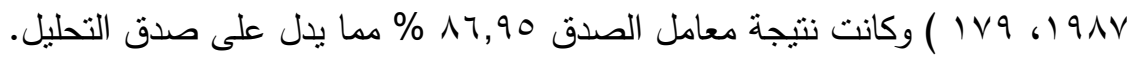
هـ.معامل ثبات التحليل: للتأكد من ثبات التحليل تم إعادة عملية التحليل وفق الخطوات التهل السابقة

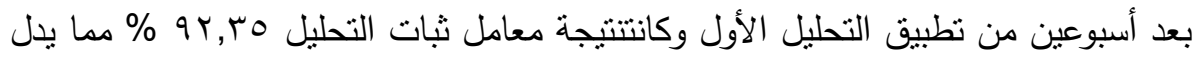
على صدق وثبات التحليل. ولذلك يحاول البحث الحالى إعداد تصور مفترح لمنهج الرياضيات فى ضوء استراتيجيات

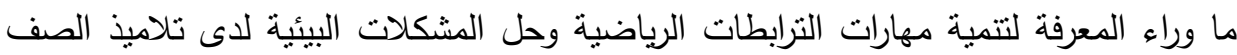
السادس الابتدائى. r. تحديد أهداف التصور المقترح. الهيهف العام: تمثل الهدف الرئيسى من التصور المقترح فى تتمية مهارات الترابطات الرياضية

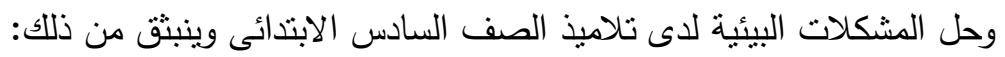

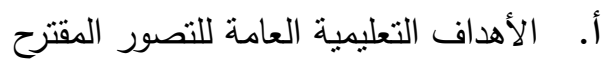
ب. أهداف متعلقة بتتمية مهارات الترابطات الرياضية ج. أهداف متعلقة بتتمية مهارات حل المشكلات البيئية ז. إعداد التصور المقترح لمنهج رياضيات الفصل الدراسى الثانى: نم اعداد التصور المقترح لمنهج رياضيات الفصل الدراسى الثانى ونم عرضه على مجموعة من المتخصصين فى 
المناهج وطرق التدريس فى الرياضيات والبيئة لإبداء ارائهم فى بناء التصورالمقترح وبناء على موافقة السادة المتخصصين تم وضع التصور المقترح.

ثالثا: ما صورة وحدتين من التصور المقترح لمنهج الرياضيات لتلاميذ المرحلة الابتدائية ؟تم الإجابة عن هذا السؤال من خلا: تم بناء الوحدتين المقترحتين فى الرياضيات

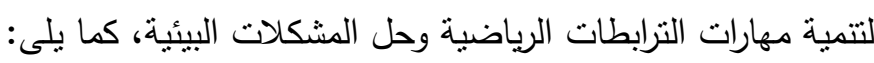

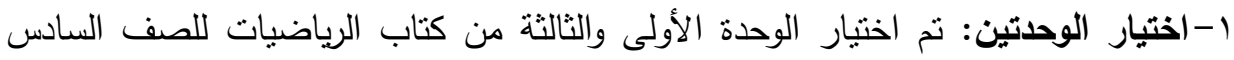

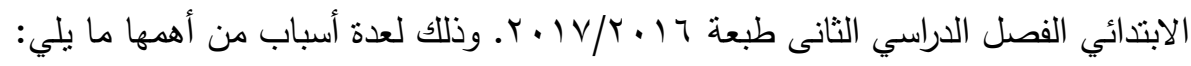

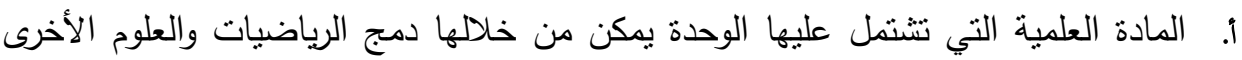
والبيئة لتتمية النرابطات الرياضية وإكساب المعارف والسلوكيات نحو مهارات حل المشكلات البيئية .

ب. المدة الزمنية لتدريس الوحدتين كبيرة نسبيا ( خمسة أسابيع وفترة ) بواقع احصص

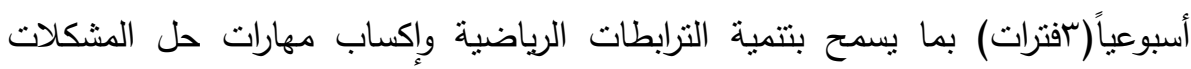

ץ-تحديد هدف الوحدتين المقترحتين: تم وضع هدف رئيس للوحدتين المقترحتين يتمثل فى "

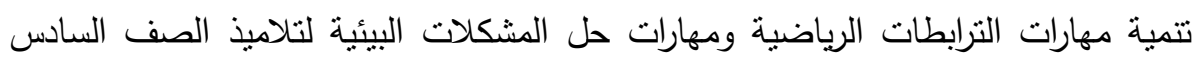

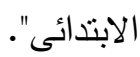

الأهداف الإجرائية: بعد الانتهاء من تدريس الوحدتين ينبخى أن يكون التلميذ قادرا على أن: أ. يتعرف خطوات حل المشكلة. ب. يتعرف على العلاقات بين الأفكار الرياضية واستخدامها.

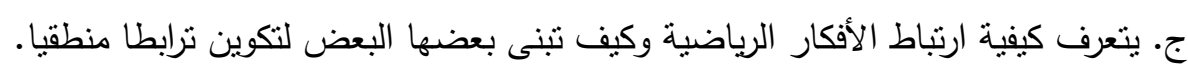
د. يتعرف كيفية استخدام الرياضيات فى سياق خارج الرياضيات. هـ ـ يستتتج الترابطات بين الرياضيات والمواد الدراسية الأخرى. • ويمكن قياس تلك الأهداف عن طريق الثقويم الثنامل المستمر، والاختبارات والمقاييس المختلفة.

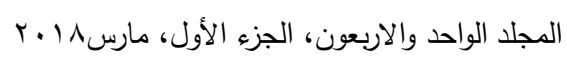


ץ-إعداد محتوى الوحدتين المقترحتين: على ضوء أهداف التصور المقترح .تم وضع محتوى الوحدتين بعد الاطلاع على الكتب والمراجع والرسائل العلمية التى تعرضت لموضوع الهوع البحث. وقد تم الإبقاء علي العناصر الجوهرية بمحتوي الوحدنين (الوحدة الأولى والثالثة) والمقررتين

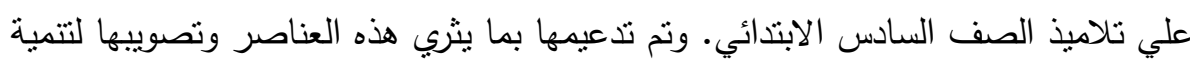
الترابطات الرياضية وحل المشكلات البيئية.

ع- الوسائط التعليمية المستخدمة: المجسمات - السبورة - أوراق نشاط متعددة ومنتوعة نوزع على التلاميذ - لوحات ورقية لأثنكال هندسية مختلفة - ورق مقوى - جداول الاستراتيجيات

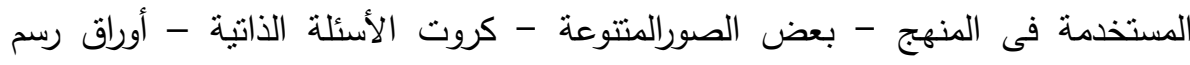
ه- الخطة الزمنية لتريس الوحتثين المقترحتين: تم تدريس الوحدة الأولى والثالثة التى تتضمن كلا منها أربعة دروس فى بس حصة (17 فترة ) طبقا لخطة الوزارة بهدف نتمية الترابطات الرياضية وحل المشكلات البيئية ؟- استراتيجيات التعليم والتعلم المستخدمة: العصف الذهنى - النمذجة - النساؤل الذاتى وحئ

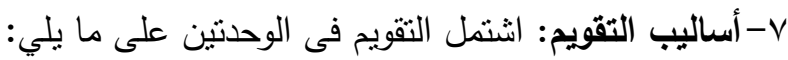
أ. تقويم بنائي ( مستمر): هو تقويم مستمر منذ بداية تدريس الوحدتين المقترحتين وحتى نهايته،

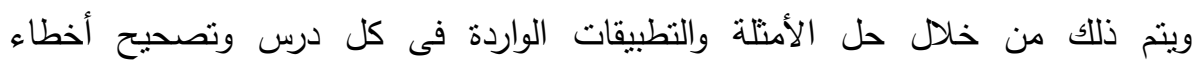
التلاميذأثناء عرض الدرس.وكذلكالتقويم فى نهاية كل درس حتى يتم التأكد من تحقيق أهداف الدرس واستيعاب التلاميذ له. ب. تقويم ختامي (نهائي): وذللك بتطبيق مقياس لحل المشكلات البيئية( من إعداد الباحثة) واختبار الترابطات الرياضية.( من إعداد الباحثة ) بعد دراسة الوحدنين ككل. 1-ضبط الوحلتين: نم عرض الوحدتين على مجموعة من خبراء فى المناهج وطرق التدريس

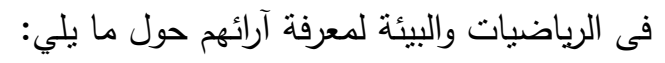
أ. دقة المعلومات العلمية الواردة فى محتوى الوحدنين. ب. البناء المنهجي من حيث الأهداف.والمحتوى.وأساليب التقويم المقترحة. لونئ. 


$$
\text { د. د. مناسبة الوحدنين لتلاميذ الصف السادس الابتدائى. }
$$

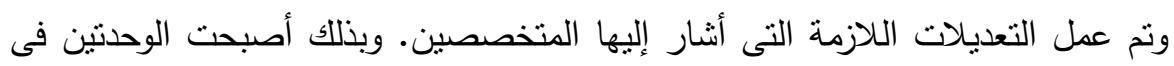
صورتهما النهائية وجاهزتان للتجريب.

9-دليل المعلم للوحاتين المقترحتين: تم بإعداد دليل للمعلم فى الوحدتين موضوع التجريب

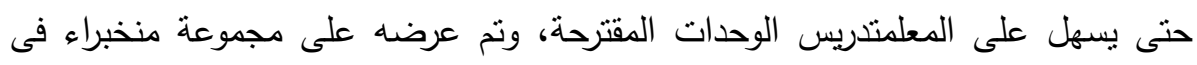

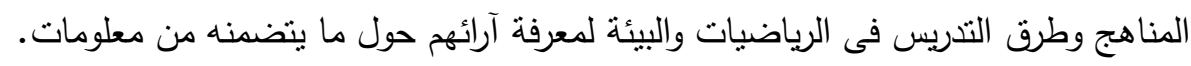

رابعاُ: تحديد فاعلية المنهج المقترح فى تتمية مهارات الترابطات الرياضية وحل المشكلات البيئية لاى تلاميذ الصف السادس بالمرحلة الابتدائية وذلك كما يلى: () إعداد اختبار مهارات الترابطات الرياضية للوحتين: تم إعداد اختبارمهارات الترابطات الرياضية بهدف التعرف على مستوى التلاميذ.وقد مر الاختبار بالخطوات التالية: أ. الأهمية النسبية لموضوعات وحدثين الأعداد الصحيحة والبيئة الأنظف.وحدة الهندسة

$$
\text { والقياس فى المساحات الخضراء }
$$

ب.نم اعداد جدول المواصفات للاختبار، ويفيد جدول المواصفات فى تحقيق صدق الاختبار

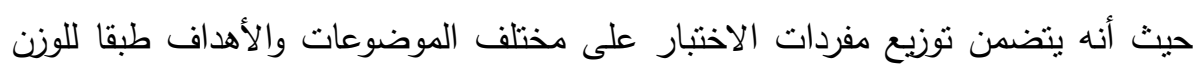
النسبي فى بنية المحتوى، والأهمية النسبية لموضوعات وحدتين الأعداد الصحيحة والبيئة الأنظف، وحدة الهندسة والقياس فى المساحات الخضراء بناءا على عدد الاهدة الصفحات

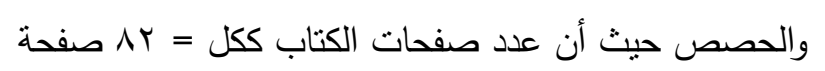


جدول(1):الأهمية النسبية لموضوعات الوحدتين وتوزيع مفردات اختبار مهارات الترابطات الرياضية

\begin{tabular}{|c|c|c|c|c|c|c|}
\hline المفردات & رقم المفردة & الحصصد & المئوية & الصفحات & موضوعات الوحدتين & b \\
\hline r & $\varepsilon-1$ & $\varepsilon$ & $\%) r, \vee q$ & $\varepsilon$ & مجموعة الأعداد الصحيحة فى البئي & 1 \\
\hline r & $9-1$ & $\varepsilon$ & $\% \curlyvee, \wedge 9$ & r & ترتيب الأعداد الصحيحة فى البيئة & r \\
\hline 9 & $\begin{array}{l}-\varepsilon-r-r \\
-\wedge-V-\uparrow \\
|\wedge-| 1-q\end{array}$ & $\varepsilon$ & $\% \backslash \vee, Y \leq$ & 0 & جمع وطرح الأعداد الصحيحة فى الخدراء & r \\
\hline 7 & $\begin{array}{l}-1 \cdot-0-r \\
-11-11 \\
11\end{array}$ & $\varepsilon$ & $\% \backslash \Gamma, \vee q$ & $\varepsilon$ & ضرب وقسمة الأعداد الصحيحة & $\varepsilon$ \\
\hline$\varepsilon$ & $\begin{array}{l}-19-17 \\
r r-r .\end{array}$ & $\varepsilon$ & $\% 1 \cdot, r \varepsilon$ & r & المسافة بين نقطتين فى مستوى الأحداثيات & 0 \\
\hline r & $19-17$ & $\varepsilon$ & $\% \backslash r, \vee q$ & $\varepsilon$ & 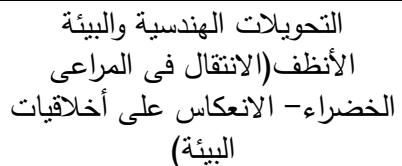 & 7 \\
\hline$\varepsilon$ & $\begin{array}{l}\text {-IS-IY } \\
\text { rO- r }\end{array}$ & $\varepsilon$ & $\% 1 \cdot, r \leq$ & r & مساحة الدائرة والتوازن البيئى & $\checkmark$ \\
\hline r & $\begin{array}{c}-Y 1-10 \\
r \leq\end{array}$ & $\varepsilon$ & $\%) r, \vee q$ & $\varepsilon$ & المكعب ومتوازى الجانبية والكلية لكل من المسنطيلات ونشر البئئى & $\wedge$ \\
\hline & & rt & $\% 1 \ldots$ & rq & المجموع & 9 \\
\hline
\end{tabular}

ونظرا للترابط بين فروع الرياضيات وبعضها فقد نتنرك أكثر من مفردة فى تلك المهارة، وبالتالى يزيد إجمالى عدد المفردات فى الجدول عن عدد المفردات فى اختبار مهارات الترابطات الرياضية. ويناءاً على هذا التحليل تم وضع اختبار مهارات الترابطات الرياضية وإعداد مفرداته. ج. تحدبد مهارت الاختبار .وهى: • مهارة التعرف على العلاقات بين الأفكار الرياضية. • مهارة التعرف على الرياضيات واستخدامها فى البيئة. 
• مهارة التعرف على الرياضيات واستخدامها فى العلوم الاخرى.

د. إعداد مفردات اختبار مهارات الترايطات الرياضية: تم إعداد مفردات اختبار مهارات التهريات الترابطات الرياضية فى ضوء الأهمية النسبية لموضوعات الوحدة ويتضمن الاختبار نوعين

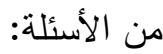
الأول: أسئلة موضوعية ومن أمتلنها الاختيار من متعدد.الإكمال. الثانى: أسئلة مقالية. هـ. صبياغة مفردات الاختبار: تمت صياغة مفردات الاختبار بما يتلاءم مع قياس الأهداف

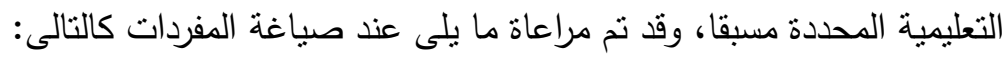

\section{بالنسبة لمفردات الأسئلة الموضوعية:}

- أن ت أنكون كل مفردة خاصة بجزء جوهري في الوحدة.

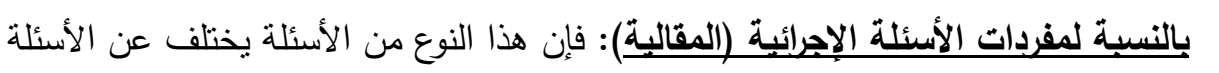

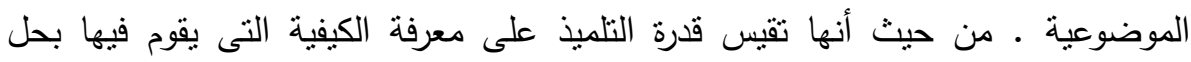

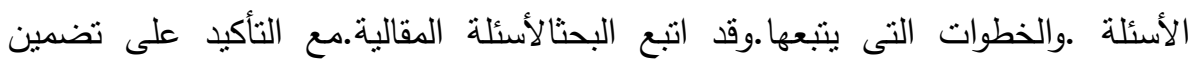
الترابطات بين الرياضيات والعلوم الدراسية الأخرى وتضمين مهارات حل المشكلات البيئية

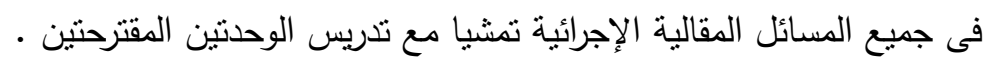
و • الصورة النهائبة للاختبار: تكون الاختبار من خمسة وعشرون مفردة و قسم إلى جزأين: الأول: ( الجانب الموضوعي ) يتكون من عشرون مفرده ويمثلون سؤالين بإجمالي (• بدرجة) .

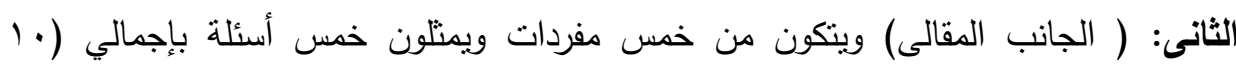

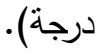

ز ز ضبط الاختبار

• صدق الاختبلد: تم عرض الاختبار على مجموعة من المتخصصين فى مجال الرياضيات

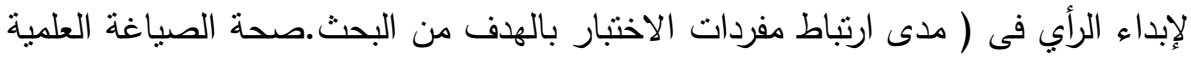
واللغوية لمفردات الاختبار .مدى مناسبتها لمستوى تلاميذ الصف السادس الابتدائى.وضوح تعليمات الاختبار ) وبعد إجراء التعديلات اللازمة أصبح الاختبار جاهزا للتطبيق.

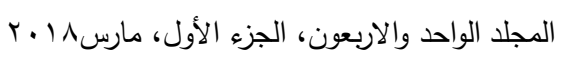


• الادراسة الاستطلاعبة :تم تطبيق الاختبار على ( • ب) تلميذ كعينة استطلاعية من تلاميذ الصف السادس الابتدائى من تلاميذ مدرسة ابن خلدون الابتدائية بإدارة بنها التعليمية.ومن لإنها غير عينة البحث الأصلية وذلك بهدف التعرف على مدى فهمه للاختبار ووضوح

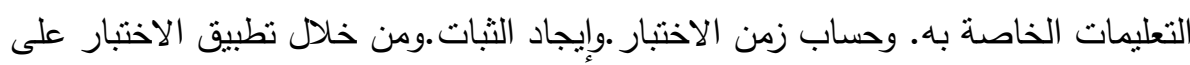
العينة الاسنطلاعية استخلصت الباحثة مدى تقهم العينة لمفردات الاختبار من خلادل إجاباتهم. • حساب زمن الاختبار:تم تحديد الزمن عن طريق حساب متوسط الزمن الذى استغرقه أول وأخر تلميذ فى حل الاختبار . ثبات الاختبارِ نم بالتأكد من ثبات نتائج الاختبار بإعادة نطبيق الاختبار مرة أخرى بفاصل

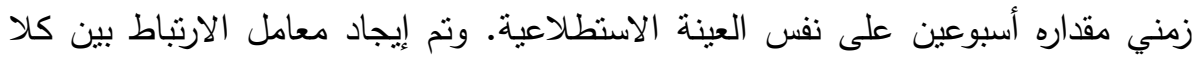

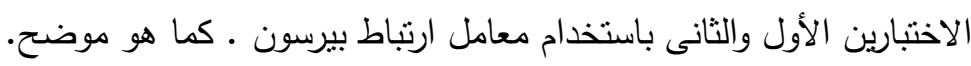

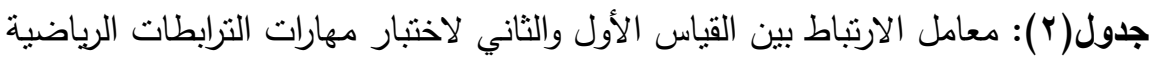
ن

\begin{tabular}{|c|c|c|c|c|c|}
\hline معامل الثبات & الانحراف & المتوسط & الانحراف & المتوسط & \\
\hline$\cdot, \Lambda \cdot r$ & 1, ror & Ir, $\leqslant 0$. & 1, & $1,90 \ldots$ & الرياضية \\
\hline
\end{tabular}

$$
\text { عند مستوي دلالة (0. (·) }
$$

يتضح من الجدول السابق أن الاختبار حقق معامل ارتباط جيدة مما يدل أن محتوياته

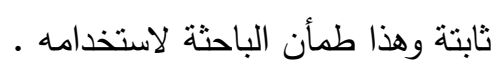
r) إعداد مقياس مهارات حل المشكلات البيئية للتصور المقترح: تم إعداد مقياس مهارات حل لاتهات

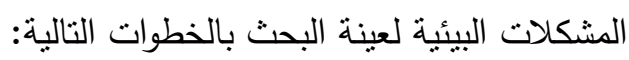
أ. تحبد الهيف من المقياس: يهدف المقياس إلى قياس مهارة حل المشكلات البيئية التى بلى التئية اكتسبها تلاميذ الصف السادس الابتدائى والتى يسنطيع من خلالها تحديد المشكلة البيئية واقتراح حلول للتغلب عليها.وتقييم هذا الحل فى ضوء الوحدتين المقترحتين التى تم تدريسهما 
• تحديد أبعاد المقياس:تم تحديد أبعاد المقياس فى ضوء المشكلات البيئية التى تم تضمينها

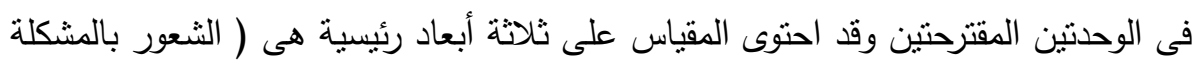
البيئية وتحديدها.|قتراح حلول للتغلب على المشكلة البيئية.تقييم حل المشكلة) ب.إعداد المقباس:تم إعداد المقياس على صورة ثلاثة مجموعات من العبارات تمثل الأبعاد

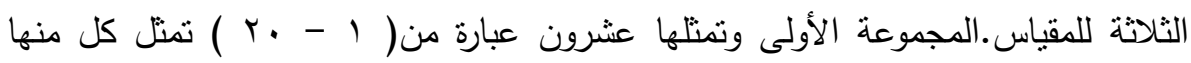

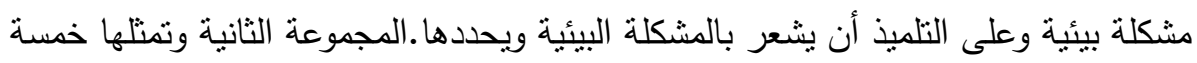

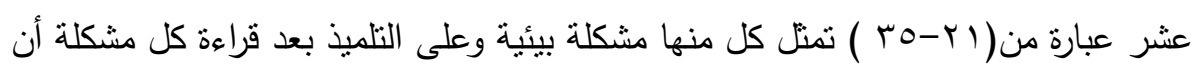

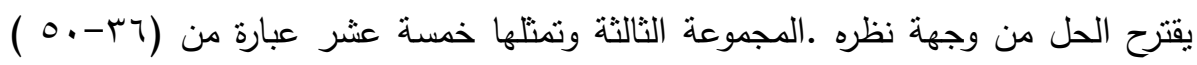
تمثل كل منها إحدي الحلول وعلي التلميذ تقييم الحل.

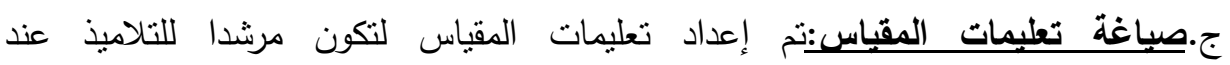
الإجابة.وطلب من التلاميذ قراءة العبارات جيداوالتفكير فيها قبل إعطاء الاستجابة التي تعبر عنرأيه .

د. صدق استمارة المقياس:بعد الاتتهاء من إعداد المقياس في صورته الأولية تم عرضه على عنى

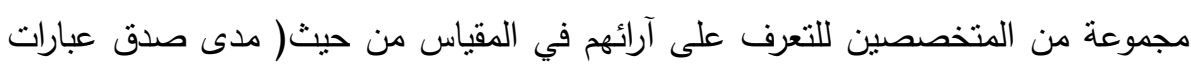

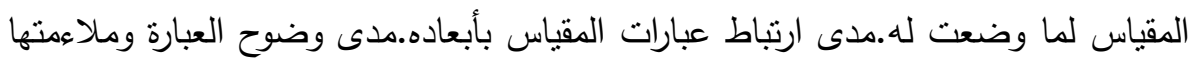
لتلاميذ الصف السادس الابتدائي.حذف أو إضافة مايرونه مناسباً).

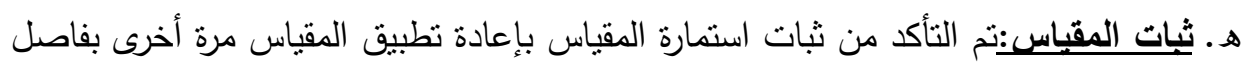

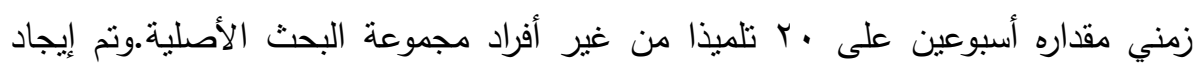

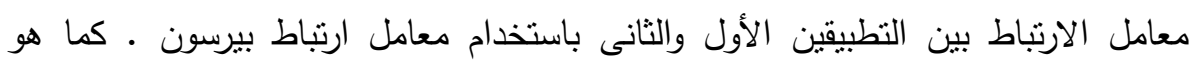

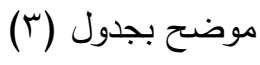


جدول(r): معامل الارتباط بين القياس الأول والثاني لمقياس مهارات حل المشكلات البيئية

\begin{tabular}{|c|c|c|c|c|c|c|}
\hline \multirow{2}{*}{ معامل } & \multicolumn{2}{|c|}{ التطبيت الثاني } & \multicolumn{2}{|c|}{ التطبيق الأول } & \multirow{2}{*}{ العبارات } & \multirow{2}{*}{ حل المشيكلات } \\
\hline & الانحراف & المتوسط & الانحراف & المتوسط & & \\
\hline$\cdot, 7 \wedge \vee$ & r,vqr & 11,70 & $1, \wedge 99$ & $1 V, 10$ & $r \cdot$ & بالمشكلة البيئية \\
\hline • & Y,97т & $1 \leqslant, \wedge$. & $1, \mathrm{~V} / \mathrm{I}$ & $1 T, 00$ & 10 & اقتراح حلول \\
\hline$\cdot, Y_{Y}$ & r,OYT & $1 \leqslant, 90$ & $r, 11 \leq$ & $1 \leq, .0$ & 10 & تقييم حلة المشكلة \\
\hline
\end{tabular}

$$
\text { عند مستوي دلالة (0., (·) }
$$

يتضح من الجدول السابق أن المقياس حقق معاملات ارتباط عالية مما يدل أن المقياس بتمتع بثبات مكوناته الفرعية، وهذا طمأن الباحثة لاستخدامه.

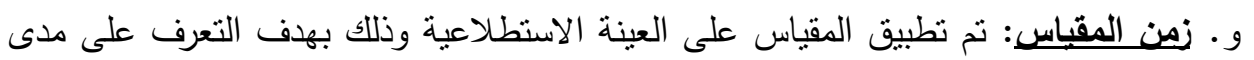

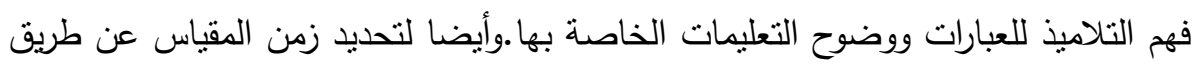

حساب منوسط الزمن الذى استغرقه أول وأخر تلميذ فى حل الاختبار .فكان • ــ دقيقة . ز. الصورة النهائية للمقياس: يوضح جدول (ع) توزيع مفردات المقياس فى صورته النهائية وما يتضمنه من محاور بيئية.وبناءا على آراء السادة المتخصصين تم حذف بعض اءل العبارات والتي تمثل مواقف مختلفة لعدم مناسبتها للمرحلة العمرية.وبذلك انتهت الباحثة إلى لم أم عبارة تمثل كلا من مهارات ( الثعور بالمشكلة البيئية .واقتراح الحل من وجهة نظر التلميذ .وتقييم

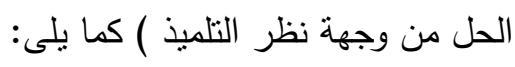

\begin{tabular}{|c|c|c|c|c|}
\hline النببة المئوية & المئوية & المفردات & أرقام العبارات & الأبعاد \\
\hline$\% \varepsilon$. & $\% \varepsilon$. & $r$. & $r \cdot-1$ & الشعور بالشكلة البيئية وتحديدها \\
\hline$\%$ \%. & $\% r$. & 10 & $r_{0}-r_{1}$ & اقتراح حلول للتغلب علثالمشكلة \\
\hline$\% r$. & $\% r$. & 10 & $0 .-r_{4}$ & تقييم حل المشكلة \\
\hline
\end{tabular}

جدول(§) : مقياس مهارات حل المشكلات البيئية فى صورته النهائية 
r) اختيار العينة: تم اختيار مجموعة من تلاميذ الصف الساد الابتدائي بمدرسة ابن خلدون

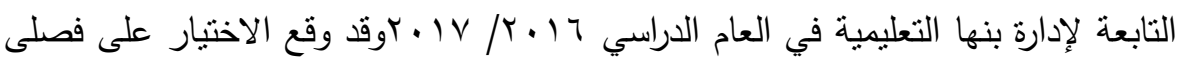

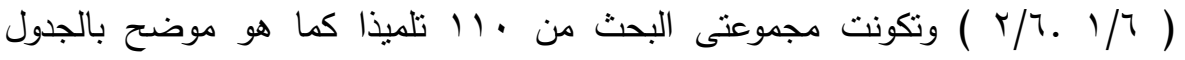

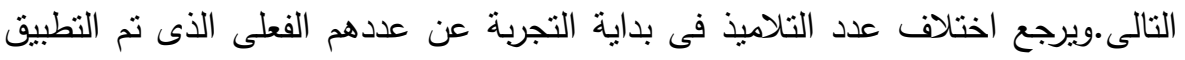
عليه لعدة أسباب منها:الغياب المتكرر لبعض التلاميذ -استبعاد التلاميذ الراسبون من العام

السابق

جدول(•): عينة البحث النهائية

\begin{tabular}{|c|c|c|c|}
\hline العدد الألى تم تطبيق & العدد فى بداية التجرية & المجموعة & الفصل \\
\hline$\leqslant 0$ & 00 & التجربيية & $1 / 7$ \\
\hline ₹0 & 00 & الضابطة & $Y / T$ \\
\hline
\end{tabular}

التصميم التجريبى: نم استخدام المجموعات المتكافئة فى التصميم التجريبى وذلك بتكوين مجموعتين متكافئتين (إحداهما ضابطة والأخرى تجريبية )، واستخدمت الباحثة التطبيق القبلى لثى والبعدى للمجموعتين لدراسة الفروق وحساب دلالتها بين المجموعتين

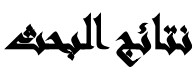

أولاً: نتائج اختبار مهارات الترابطات الرياضية: يوجد فرق دال احصائيا بين منوسط درجات تلاميذ المجموعة التجريبية والضابطة فى القباس البعدى فى اختبار مهارات النرابطات

$$
\text { الرياضية لصالح المجموعة التجريبية }
$$

جدول(؟): الفرق بين منوسط منوسط درجات تلاميذ المجموعة التجريبية والضابطة فى القياس البعدى فى اختبار مهارات الترابطات الرياضية

\begin{tabular}{|c|c|c|c|c|c|c|}
\hline مستوى الدلالة & قيمة T & الدرجية & الانحراف & المتوسط & الفتغير & المتغير الرئيسي \\
\hline \multirow{2}{*}{ 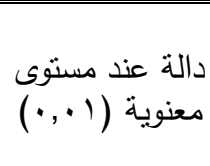 } & \multirow{2}{*}{$7,7.9$} & \multirow{2}{*}{$\Lambda \Lambda$} & $r, 19 r$ & $r o, v$. & الضابطوعة & \multirow{2}{*}{ التتبار مهارات } \\
\hline & & & $1, r \circ \varepsilon$ & $r \Lambda, 19$ & التجرموعة & \\
\hline
\end{tabular}

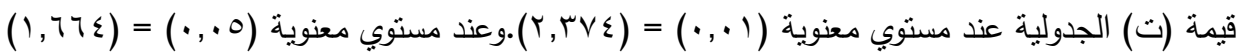

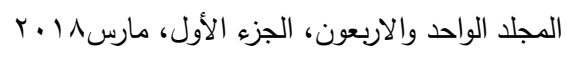


يتضح من الجدول السابق أن القياس البعدي للمجموعة الضابطة (ro,V) بانحراف

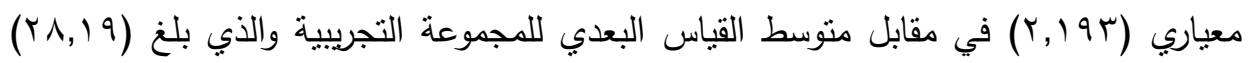

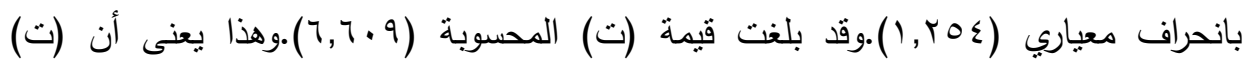

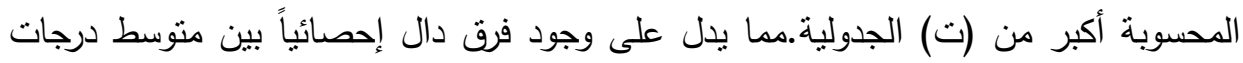

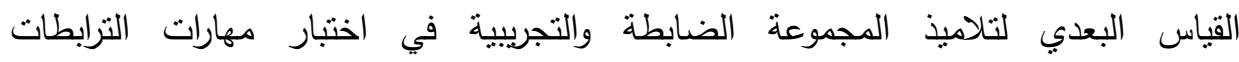
الرياضية.لصالح المجموعة التجريبية. • مناقشة نتائج اختبار مهارات الترابطات الرياضية: تعزى الباحثة التحسن الذى طرأ على لـى درجات مهارات الترابطات الرياضية لدى تلاميذ المجموعة التجريبية فى القياس البعدى لهی مقارنة بالقياس البعدى للمجموعة الضابطة إلى عدة عوامل من أهمها؛ المنهج الذى تم

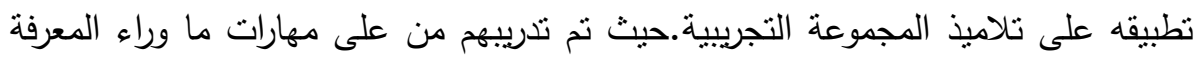
واستراتيجياتها والتى تسهم فى زيادة الوعى بالعمليات المعرفية التى يقوم بها الفرد.وتتظيمها

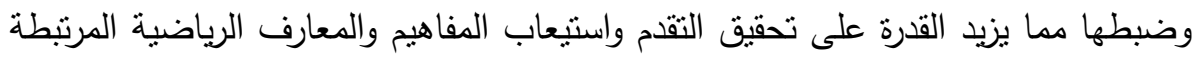
بالدرس.وأيضا يرجع إلى استخدام استراتيجيات ماوراء المعرفة والتى أدت إلى استيعاب التئي

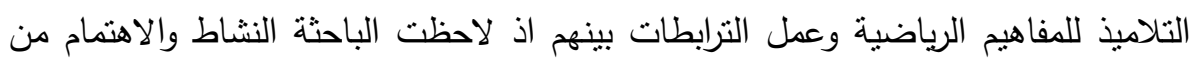
التلاميذ من خلال تفاعلهم ونشاطهم فى ابتكار الأمتلة البيئية والترابط بينها وبذللك أصبح متعلم مستقل وأكثر وعيا بتفكيره ثانياً: نتائج مقياس مهارات حل المشكلات البيئية: يوجد فرق دال احصائيا بين متوسط درجات مجموعتى البحث الضابطة والتجريبية بعديا في مقياس مهارات حل المشكلات البيئية لصالح المجموعة التجريبية . 
جدول(V): الفرق بين منوسط درجات مجموعتى البحث الضابطة والتجريبية بعديا في مقياس مهارات حل المشكلات البيئية

\begin{tabular}{|c|c|c|c|c|c|c|}
\hline الدلاليّة & قيمة T & الدرجية & المعياري & المتوسط & الفرعير & المتغير الرئيسي \\
\hline \multirow{2}{*}{ مسنوي } & \multirow{2}{*}{$T V, \cdot T_{O}$} & \multirow{2}{*}{$\Lambda \Lambda$} & $0,9 Y 7$ & $79, \wedge \vee$ & الضجموعة & \multirow{2}{*}{ حل المشكيلات } \\
\hline & & & $r, q \leq r$ & 97,07 & التجريبية & \\
\hline
\end{tabular}

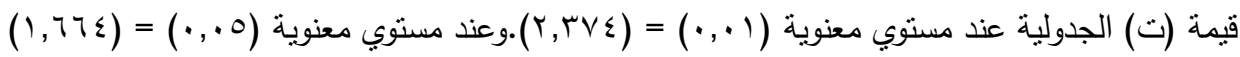

يتضح من الجدول السابق الفرق بين متوسط درجات القياس البعدي لتلاميذ المجموعتين الضابطة والتجريبية فى مقياس مهارات حل المشكلات البيئية.فقد جاء متوسط القياس البعدي

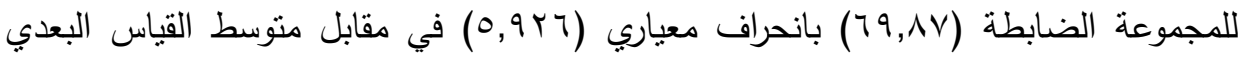

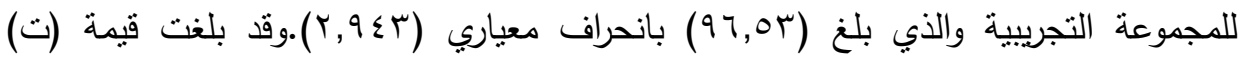

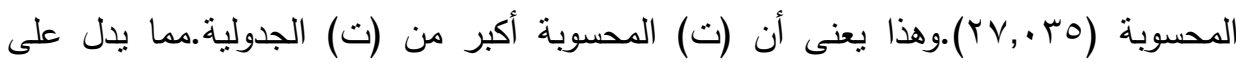
وجود فرق دال إحصائًاً بين متوسط درجات القياس البعدي لتلاميذ المجموعتن الضابطة والتجريبية فى إجمالي المقياس.لصالح المجموعة التجريبية. • مناقشة نتائج مقياس مهارات حل المشكلات البيئية: تعزى الباحثة التحسن الذى طرأ على لى درجات مقياس مهارات حل المشكلات البيئية لدى تلاميذ المجموعة التجريبية فى القياس

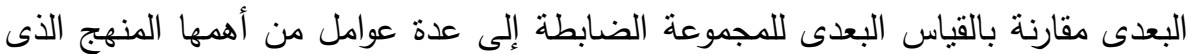
تم تطبيقه على تلاميذ المجموعة التجريبية، حيث تم تدريبهم على مهارات ما وراء المعرفة واستراتيجياتها والتى تسهم فى زيادة الوعى بالعمليات المعرفية التى يقوم بها الفرد.وتتظيمها وضبطها مما يزيد القدرة على تحقيق التقام فى جميع المساعى المعرفية ومنها حل المشكلات البيئية وذلك من خلال تركيز انتباه التلاميذ على المشكلة ذاتها وما تتضمنه من معلومات ومراقبة عملية التخطيط للحل .وتقويم أنفسهم وقدراتهم. 
كما أن استراتيجيات ما وراء المعرفة من شأنها أن تجعل الفرد على وعى بما يقوم به من

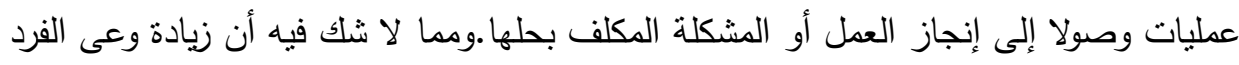
بذاته يزيد من درجة فهمه لجوانب العملية وزيادة قدرته على الفهم. وقد أكدت ماير (Mayer.1998.49) على أن حل المشكلات الناجح والفعال ينطلب نوافر

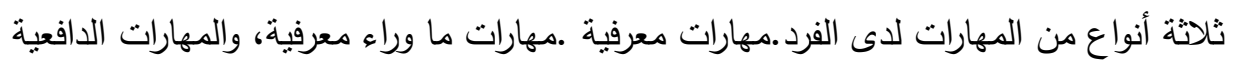
فكلما كان التلميذ أكثر وعيا بمهارات واستراتيجيات ما وراء المعرفة كلما أصبح أكثر كفاءة فى حل المشكلات البيئية. كما أن للمعلم دورا كبيرا فى وجود هذه الفروق حيث أنه يقوم بدوره كموجة بين التلاميذ

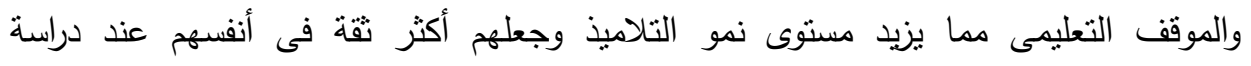
المشكلات كما أن ممارسة التلاميذ لبعض الأنشطة التى تتضمن بعض بهر العمليات ما وراء

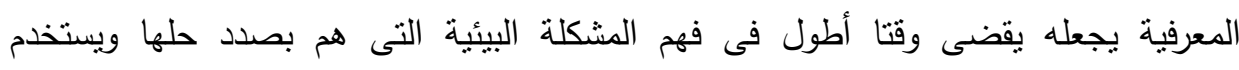

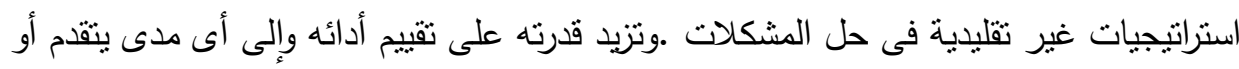
يتعثر وما هى البدائل التى يستخدمها لتحقيق هدفة. أن حل المشكلات ينطلب من الفرد وضع خطة لذاته لضمان القيام بهذه العملية .كما تتطلب مراقبة الفرد لنفسه أثناء التقدم فى الأداء ليلاحظ مدى فاعلية الخطة الموضوعة والاستراتيجيات المستخدمة ؟ وهل يحتاج إلى تغيير الاستراتيجية ؟ وهل أنجز العمل فى الوقت

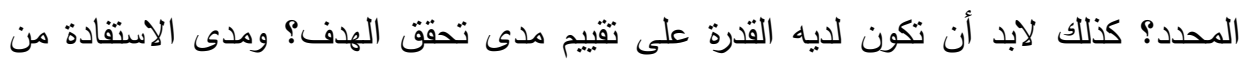

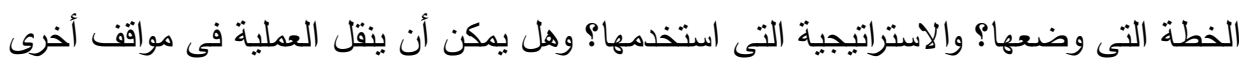
ومشكلات جديدة؟ وقد أثنارت العديد من الدراسات والبحوث إلى فاعلية التدريب على استراتيجيات ما وراء

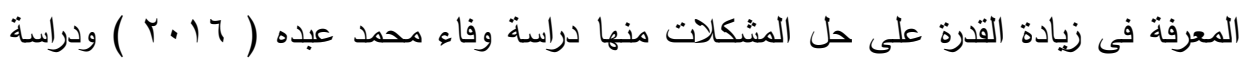

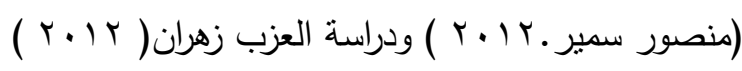




\section{اللموصياهيت}

ا. إظهار مناهج الرياضيات للدور الوظيفى لاستراتيجيات ما وراء المعرفة فى تتمية الترابطات

الرياضية ومهارات حل المشكلات البيئية.

r. الاهتمام بتطوير مناهج الرياضيات وتضمين المشكلات البيئية بهافى مراحل التعليم بصفة عامة و المرحلة الابندائية بصفة خاصة.

r. استخدام استراتيجيات ما وراء المعرفة ومهارات حل المشكلات فى تدريس وحدات منهج

$$
\text { الرياضيات للصف السادس الابندائى. }
$$

ع. الاهتمام بربط منهج الرياضيات ببيئة التلميذ المحلية ونوظيفها لخدمة هذه البيئة.

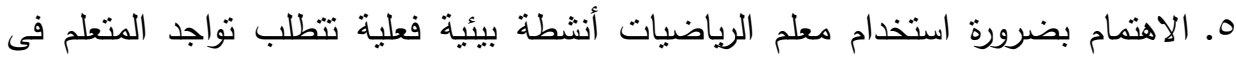
موقف يستوجب استخدام توظيف المحتوى المعرفى للتعامل معه.

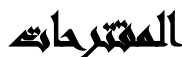

1. إجراء دراسات حول تضمين المشكلات البيئية فى مناهج الرياضيات ومناهج العلوم

$$
\text { الأخرفى المراحل الدراسية الأخرى. }
$$

r r إجراء دراسات وبرامج تتمية مهنية تساعد على تدريب المعلم أثثاء إعداده فى كليات التربية

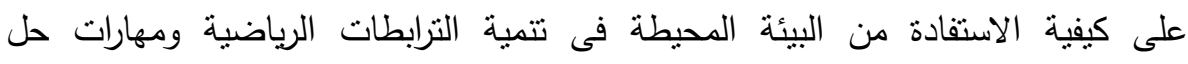

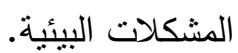

r. إجراء دراسات حول فاعلية استخدام استراتيجية ماوراء المعرفة في تتمية متغيرات تابعة أخرى

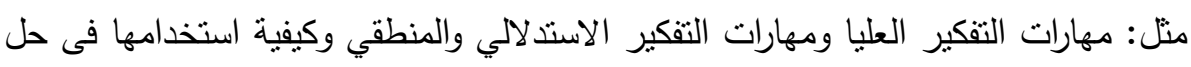

$$
\text { المشكلات البيئية. }
$$

\section{المرالئen}

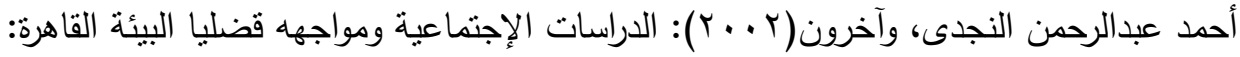
دار القاهرة

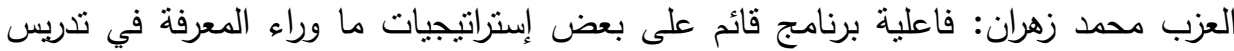
الرياضيات على تتمية مهارات الترابطات الرياضية لدى تلاميذ المرات التهلة

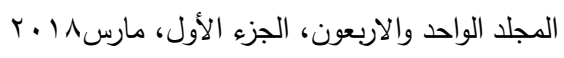


الإعدادية، مجلة تربويات الرياضيات المجلد الخامس عشر - يوليو r r ب

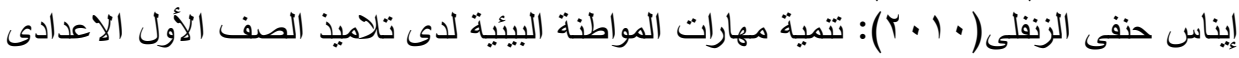

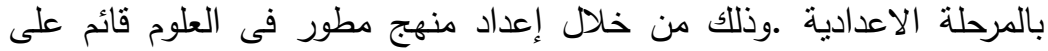
الإستقصاء وحل المشكلات، رسالة دكتوراه.معهد الدراسات والبحوث البياتئية

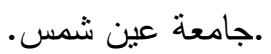

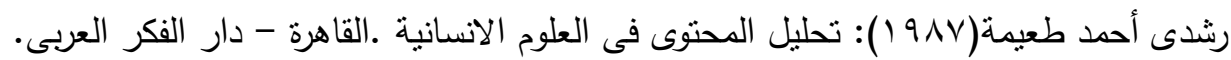

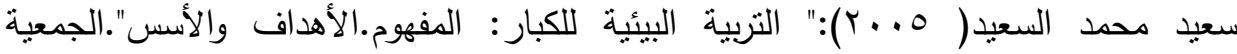

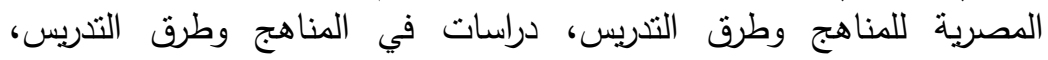

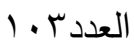

عصام أحمد الغزالى(7 ( • Y): فاعلية استراتيجية قائمة على الترابطات الرياضية في تتمية القوة

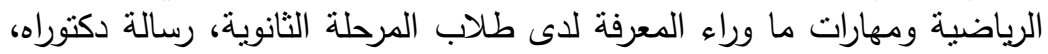
كلية التربية، جامعة كفر الشيخ.

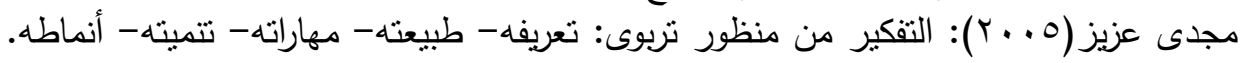

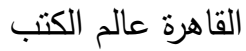

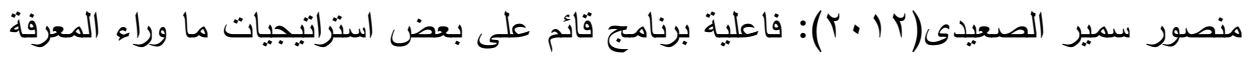

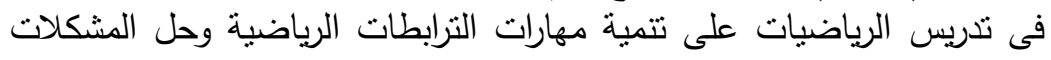

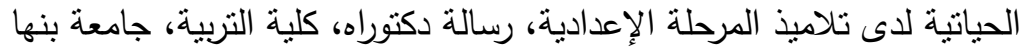

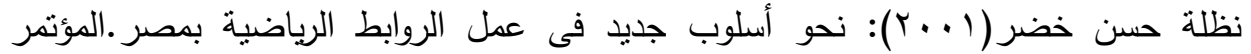

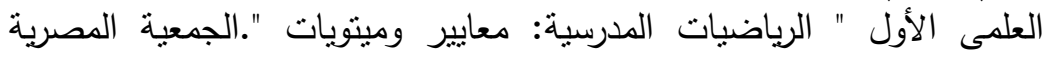

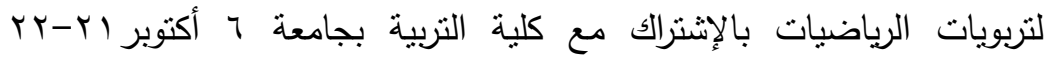

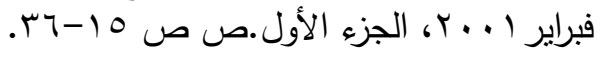

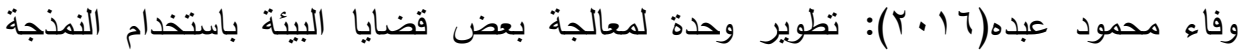

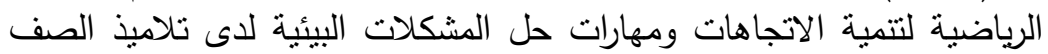

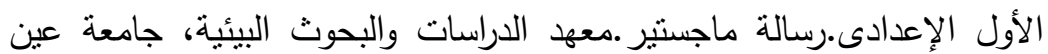
شمس.

Francis Wagaba.David F. Treagust.et al..(2016): Using metacognitive strategies in teaching to facilitate understanding of light concepts among year 9 students.Journal Research in Science \& Technological Education Volume 34.2016 - Issue 3 .Pages 253-272.

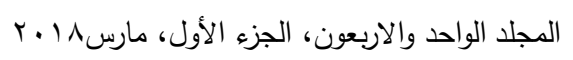


FurtunaTewolde.et al..(2016): Learning Strategies and Metacognition in Students with Learning Disabilities.University of North Florida.

Golriz Pour Mohaddes.et al..(2016): The Effectiveness of Metacognitive Strategies of SQP4R on Decreasing Impulsiveness of Students with Mathematic learning Disability.International Journal of Humanities and Cultural Studies (IJHCS) ISSN 2356-5926.

Holly Andersen(2016): The Academic and Psychological Effects of Teaching Students with Learning Disabilities to Solve Problems Using Cognitive and Metacognitive Strategies.School of Education Student Capstones and Dissertations .4112.Hamline university.

Mayer.Richard E . (1998): Cognitive.Metacognitive and Motivational Aspects of problem solving .Instractionalscience.vol. 26.pp.49-63

Nall.KatherineLigon (2011): Providing Teachers with Research- and Cognitive Learning Theory-based Instructional Materials for Promoting Students' Metacognition: A Replication Study of A Community College Mathematics Teacher and Curriculum Reformation Program .Ph.D.Florida Institute of Technolgy.Florida.

Pennequin.Valerie \& Sorel Olivier and Airgny.Mertial (2010): Meta cogrition Exective Functions and Aging: The Effect training in the use of Metacognitive skills to solve mathematical word problems.Journal of Adult Development.V. 17

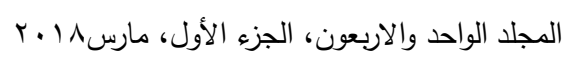


معهد الدراسات والبحوث البيئية - جامعة عين شمس لمس لمس

\title{
MATHEMATICS CURRICULUM USING \\ METACOGNITIVE STRATEGIES TO DEVELOP \\ MATHEMATICAL CONNECTION SKILLS AND \\ SOLVING EVIRONMENTAL PROBLEMS AMONG \\ PRIMARY SCHOOLS STUDENTS
}

\author{
Abd-Elsamee, Azza, M. ${ }^{(1)}$;Mohamed, Reham, R. ${ }^{(2)}$ \\ and Eldeeb, Wafaa, $M$.
}

1) Faculty of Education, Ain Shams University 2) Institute of Environmental Studies and Research, Ain Shams University.

\begin{abstract}
The aim of this research is to measure the impact of the development of the mathematics curriculum in the light of the meta-knowledge strategies to develop the skills of mathematical correlations and solve the environmental problems of primary school students.especially in view of the increasing environmental problems that require the cooperation of the community members and their groups to address them. The students' book and the teacher's guide were prepared to prepare the two units (integers.cleaner environment.engineering and measurement in green spaces) As a suggested approach. The teacher's manual for the two proposed units was prepared and then taught to a group of 45 students and students from the sixth grade according to the meta-knowledge strategies that were chosen (self-questioning) and Lynne Phillips ("modeling" - brainstorming) Mathematical correlation skills consist of (25) single.and also the scale of solving environmental problems consists of (50 The results revealed a statistically significant difference between the mean scores of the experimental and control groups in the telemetry to test the mathematical correlations in favor of the experimental group. There was a statistically significant difference between the mean scores
\end{abstract}

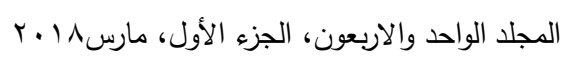


of the experimental group and the control unit. Students of the experimental and control group in the remote dimension of the environmental problem solving scale and in all his skills for the benefit of the experimental group) 